\title{
Are professors of human nutrition faculty at Canadian universities representative with respect to common social constructs of gender and race?
}

\author{
Michael I. McBurney
}

\begin{abstract}
Attributes such as sex and race/ethnicity are associated with inequities in representation. The objective of this study was to assess representation of 2 social constructs, gender and race, of professors of human nutrition in Canada. Using information publicly available October 2021, individuals with the title of assistant, associate, or full professor were identified on websites of 20 Canadian universities offering undergraduate and/or graduate degrees in human nutrition. Individuals were subjectively stratified to social constructs, i.e., white, racialized, or Indigenous, based on photographs, ethnic origin of a surname, and regional and ethnic origin disclosures on university websites, LinkedIn, social media, etc. Gender was assigned based on publicly available photographs and self-disclosed pronouns (when available). Of the 190 individuals, $80 \%$ were white, $16.4 \%$ were racialized, and $2.6 \%$ were Indigenous peoples. The majority (65.3\%) were women. In a subset with established doctoral thesis dates and dates of hire at their current institution $(n=153)$, racialized and Indigenous professors, especially assistant and associate, had earned their doctorate and been hired more recently than their white peers. This study is limited because only individuals with professorial titles were included and the assignment of social constructs for race and gender was subjective. Nevertheless, it establishes an understanding of the proportions of professors of human nutrition who are white, racialized, Indigenous, women, and men.
\end{abstract}

Novelty:

- Canadian universities strive to be equitable, diverse, and inclusive.

- One hundred and ninety professors of human nutrition were stratified using social constructs for race and gender.

- Findings: $65 \%$ Women, $80 \%$ white, $16.4 \%$ racialized, and $2.6 \%$ Indigenous

Key words: equity, diversity, inclusion, human, nutrition, faculty.

Résumé : Des attributs tels que le sexe et la race/ethnicité sont associés à des inégalités de représentation. L'objectif de cette étude était d'évaluer la représentation de deux concepts sociaux, le sexe et la race, de professeurs de nutrition humaine au Canada. À l'aide d'informations accessibles au public en octobre 2021, des individus portant le titre de professeur adjoint, agrégé ou titulaire ont été identifiés sur les sites Web de vingt universités canadiennes offrant des diplômes de premier cycle et/ou de cycles supérieurs en nutrition humaine. Les individus ont été subjectivement stratifiés selon des concepts sociaux, c'est-à-dire blancs, racialisés ou Autochtones sur la base de photographies, de l'origine ethnique d'un nom de famille et de divulgations d'origine régionale et ethnique sur les sites Web universitaires, LinkedIn, médias sociaux, etc. Le sexe a été attribué sur la base de photographies accessibles au public et de pronoms auto-divulgués, le cas échéant. Sur les 190 individus, 80 \% étaient blancs, 16,4 \%, racialisées et 2,6 \%, Autochtones. La majorité (65,3 \%) était des femmes. Dans un sous-ensemble avec des dates de thèse de doctorat et des dates d'embauche établies dans leur établissement actuel ( $n=153$ ), les professeurs racialisés et autochtones, en particulier les adjoints et les agrégés, avaient obtenu leur doctorat et avaient été embauchés plus récemment que leurs pairs blancs. Cette étude est limitée, car seuls les individus ayant des titres de professeur ont été inclus et l'attribution de concepts sociaux pour la race et le sexe était subjective. Néanmoins, cette étude établit une compréhension des proportions de professeurs de nutrition humaine qui sont blancs, racialisés, autochtones, femmes et hommes. [Traduit par la Rédaction]

Les nouveautés :

- Les universités canadiennes s'efforcent d'être équitables, diversifiées et inclusives.

- Centre quatre-vingt-dix professeurs de nutrition humaine ont été stratifiés à l'aide de concepts sociaux pour la race et le sexe.

- Résultats : $65 \%$ de femmes, $80 \%$ de blancs, $16,4 \%$ de personnes racialisées et 2,6 \% d'Autochtones.

Mots-clés : équité, diversité, inclusion, humain, nutrition, faculté.

Received 25 November 2021. Accepted 24 January 2022.

M.I. McBurney. Department of Human Health and Nutritional Sciences, University of Guelph, Guelph, ON N1G 2W1, Canada; Division of Biochemical and Molecular Biology, Friedman School of Nutrition Science and Policy, Tufts University, Boston, MA 02111, USA.

Email for correspondence: mcburnem@uoguelph.ca.

(C) 2022 The Author(s). Permission for reuse (free in most cases) can be obtained from copyright.com. 


\section{Introduction}

Privilege occurs when unearned access, benefits, and opportunities are granted to members of a social group with a high level of power (Canadian Centre for Diversity and Inclusion 2022). Attributes such as sex, race/ethnicity, religion, sexual orientation, age, and physical ability are associated with representation and power, i.e., support, assets, approval, and rewards, that may be conferred to some but not all. Despite a reputation as bastions of liberalism, racialized and Indigenous people are underrepresented among faculty at Canadian universities (Henry et al. 2017b; Universities Canada 2019) and structural gender inequality exists among natural sciences and engineering professors in Canada (Dengate et al. 2021). Women are more likely to be sexually harassed; take leave for child, parental or elder care; and voluntarily leave academic positions than males (Dryfhout and Estes 2010). Not surprisingly, career trajectories of researchers in Canada differ by gender (Appel-Cresswell et al. 2019; Witteman et al. 2019) and gender-related roles (Giannakeas et al. 2019).

The Canadian Employment Equity Act defines visible minorities as "persons, other than Aboriginal peoples, who are non-Caucasian in race or non-white in colour" and Aboriginal peoples as those who report being First Nations, Métis, or Inuit (Statistics Canada 2017). Using selected departments in the faculties of social sciences and humanities, engineering, and business/management at 5 Canadian universities, Henry et al. (2017b) examined photos and names of faculty to determine representation of people who are socially constructed as non-white, i.e., racialized, and Indigenous scholars, i.e., First Nations, Métis, or Inuit. This stimulated me to review publicly available information October 2021 on professors engaged full-time in teaching nutrition, human nutrition-related research, and service at 20 universities in Canada.

\section{Methods}

The search was restricted to individuals with the title of assistant, associate, or full professor listed on university websites offering undergraduate and/or graduate degrees in human nutrition (Table 1). Additional inclusion criteria were evidence of human nutrition-related scientific publications, teaching nutrition courses, and self-identified research focus on human nutrition. Individuals with evidence of employment elsewhere (adjunct), unpaid faculty (emeritus or retired), or appointments that are often contractually limited or temporary (clinical instructors and lecturers) were not included. The goal was to survey university professors engaged full-time in teaching, research, and service in human nutrition.

Individuals were subjectively stratified according to social constructs, i.e., white, racialized, or Indigenous, by assessing photographs, ethnic origin of a surname, and regional and ethnic origin disclosures on university websites and research affiliates, LinkedIn, social media, etc. Gender, a socially constructed characteristic of women and men, was assigned based on publicly available photographs and self-disclosed pronouns (when available). Faculty rank, current department/institution, highest degree, year highest degree conferred, institution granting highest degree, and date of hire at current institution were obtained from university websites, LinkedIn, Orcid, Library and Archives Canada - Theses Canada, Proquest dissertations and theses (accessed through Tufts University), and Google searches using 'name university PhD thesis'.

\section{Results}

From 20 universities (Table 1), 190 professors of human nutrition were identified. The professors are predominantly white $(81.0 \%)$ with $16.3 \%$ racialized and $2.6 \%$ Indigenous peoples (Table 2). Racialized (16.3\%) and Indigenous (2.6\%) professors of human nutrition are underrepresented compared with the most recently available Canadian population data with $22.3 \%$ and $4.9 \%$ classified as visible minority (racialized) or Aboriginal (Indigenous) persons, respectively (Statistics Canada 2016).
Most professors of human nutrition are women (65.3\%) and $84.7 \%$ of women are white (Table 2). Within each rank of human nutrition professors, women outnumbered men and the differential was assistant (4.1:1) > associate (1.9:1) > full (1.1:1).

In a subset with established doctoral thesis dates and dates of hire at their current institution $(n=153)$, racialized and Indigenous professors of human nutrition were found to have earned their doctorate later and to have been more recently hired than their white peers (Table 3). This observation is reinforced by the smaller standard deviation in hiring dates for racialized and Indigenous faculty, especially among assistant and associate professors. It is notable that $63 \%$ of assistant professors are white women and $<5 \%$ of assistant professors are racialized or Indigenous men.

\section{Discussion}

Women constitute half of the Canadian population (Statistics Canada 2018), obtain at least half of the PhDs earned (Reithmeier et al. 2019; Cardel et al. 2020b), and represent $65.3 \%$ of professors of human nutrition. Within professors of human nutrition, women constitute a greater proportion of assistant (81.4\%), associate (68.3\%), and full (54.8\%) professors than national proportions of assistant $(49 \%)$, associate (43\%), and full (28\%) professors who are women (Statistics Canada 2018). On average, the 20 Canadian universities have a higher proportion of racialized and Indigenous professors of human nutrition (12.8\%) than reported for faculties of social sciences and humanities (3.7\%) and lower than that in faculties of engineering (34.9\%) and business/management (24.1\%) at 5 Canadian universities (Henry et al. 2017a). Three Canadian universities did not have any racialized or Indigenous professors of human nutrition. Representation was similar across universities with small $(n \leq 5)$, medium $(n=$ $6-11)$, and large $(n \geq 12)$ numbers of professors of human nutrition ( $n \leq 5, n=6-11, n \geq 12$ ) as well as universities located in small (population $<179000, n=4$ ), medium (population $>180000$ to 1.44 million, $n=7$ ), and large communities (population $>1.44$ million people, $n=$ 9) (data not presented), i.e., $\sim 80 \%$ white, $14 \%-22 \%$ racialized, and $0 \%-$ $3 \%$ Indigenous peoples. These findings concur with those of Henry et al. (2017a) who did not find any association of institutional size or community size on representation. It is probable that the sample size was insufficient.

Racialized and Indigenous professors of human nutrition obtained their $\mathrm{PhD}$ later and were hired more recently on average than their white peers (Table 3). The greatest diversity is found among assistant professors $(22 \%$ being racialized or Indigenous) and most of these scholars have been hired since 2017. The average hiring year of racialized and Indigenous associate professors is also later than their white peers. The average hiring years for assistant and associate professors of human nutrition coincide with the launch of the Canada Research Chairs Equity, Diversity and Inclusion Action Plan, which set equity and diversity targets to support institutions in addressing underrepresentation of 4 designated groups: women, persons with disabilities, Indigenous peoples, and members of visible minorities (Canada Research Chairs 2017). Women now occupy $40.9 \%$ of Research Chairs (target $=50.9 \%$ ), $22.8 \%$ are members of visible minorities (2019 target $=15 \%$ ), and 3.4\% are Indigenous peoples $($ target $=1 \%)$ (Canada Research Chairs 2021). Among professors of human nutrition, women are not underrepresented but the proportion of racialized and Indigenous professors of human nutrition is below Canada Research Chairs targets.

The Canadian Nutrition Society (CNS), Canada's leading society that integrates disciplines and professions interested in nutrition, including nutrition scientists and professionals, healthcare/ clinical practitioners, government and policy makers, industry representatives, and trainees, created an Equity, Diversity and Inclusion Working Group in early 2021 to help develop a strategy to identify systemic barriers and mitigate biases that may limit 
Table 1. Universities included in the analysis.

\begin{tabular}{ll}
\hline University & Department \\
\hline Acadia & Nutrition and Dietetics \\
Alberta & Agricultural, Food and Nutritional Sciences \\
BC & Food, Nutrition and Health; Human Nutrition \\
Calgary & Nutrition \& Kinesiology \\
Guelph & Human Health \& Nutritional Sciences; Family Relations \& Applied Nutrition \\
Laval, Montreal & Sciences de l'agriculture et de l'alimentation \\
Laval, Quebec & Institute on Nutrition and Functional Food; Hôtel Dieu; Nutrition; Institut national \\
& de la recherche scientifique \\
Manitoba & Food \& Human Nutritional Sciences; Community Health; Pediatrics and Child Health \\
McGill & School of Human Nutrition \\
McMaster & Kinesiology; Health Sciences \\
Memorial & Biochemistry \\
Montreal & Nutrition \\
Mount Saint Vincent & Applied Human Nutrition \\
Ottawa & School of Nutrition Sciences \\
PEI & Applied Human Sciences \\
Ryerson & School of Nutrition \\
Saskatchewan & Pharmacy and Nutrition \\
Sherbrooke & Centre de recherche sur le viellissement \\
Toronto & Nutritional Sciences \\
Waterloo & Nutritional Science; Kinesiology \& Health Sciences
\end{tabular}

Table 2. Representation of 190 human nutrition professors at 20 Canadian universities.

\begin{tabular}{|c|c|c|c|c|c|c|}
\hline & \multicolumn{3}{|c|}{ Men, $n(\%)$} & \multicolumn{3}{|c|}{ Women, $n(\%)$} \\
\hline & White & Racialized & Indigenous & White & Racialized & Indigenous \\
\hline Professor & $28(14.7)$ & $10(5.3)$ & $0(0)$ & $39(20.5)$ & $7(3.7)$ & $0(0)$ \\
\hline Associate & 15 (7.9) & $5(2.6)$ & $0(0)$ & $38(20.0)$ & $3(1.6)$ & 2 (1.1) \\
\hline Assistant & $6(3.2)$ & $2(1.1)$ & $0(0)$ & $28(14.7)$ & $4(2.1)$ & $3(1.6)$ \\
\hline Subtotal & $49(25.8)$ & $17(8.9)$ & $0(0)$ & $105(55.3)$ & $14(7.4)$ & $5(2.6)$ \\
\hline Total & \multicolumn{3}{|c|}{$66(34.7)$} & \multicolumn{3}{|c|}{$124(65.3)$} \\
\hline
\end{tabular}

Table 3. Year $\mathrm{PhD}$ was conferred and year of hiring at current institution of human nutrition professors stratified by rank and apparent race when both dates were publicly available.

\begin{tabular}{|c|c|c|c|c|c|c|c|c|}
\hline & \multicolumn{4}{|l|}{ Men } & \multicolumn{4}{|l|}{ Women } \\
\hline & \multicolumn{2}{|l|}{ White } & \multicolumn{2}{|c|}{$\begin{array}{l}\text { Racialized and } \\
\text { Indigenous }\end{array}$} & \multicolumn{2}{|l|}{ White } & \multicolumn{2}{|c|}{$\begin{array}{l}\text { Racialized and } \\
\text { Indigenous }\end{array}$} \\
\hline & Mean \pm SD & $n$ & Mean \pm SD & $n$ & Mean \pm SD & $n$ & Mean \pm SD & $n$ \\
\hline \multicolumn{9}{|c|}{ Year PhD was conferred } \\
\hline Full & $1995 \pm 9.1$ & 22 & $1998 \pm 9.3$ & 9 & $1994 \pm 7.4$ & 29 & $1998 \pm 9.4$ & 6 \\
\hline Associate & $2003 \pm 7.9$ & 12 & $2006 \pm 10.0$ & 4 & $2005 \pm 6.5$ & 28 & $2013 \pm 3.5$ & 2 \\
\hline Assistant & $2012 \pm 3.7$ & 6 & $2012 \pm 4.2$ & 2 & $2012 \pm 5.3$ & 26 & $2015 \pm 4.2$ & 7 \\
\hline \multicolumn{9}{|c|}{ Year of hiring at current institution } \\
\hline Full & $2000 \pm 10.1$ & 22 & $2005 \pm 8.4$ & 9 & $2002 \pm 7.6$ & 29 & $2005 \pm 6.3$ & 6 \\
\hline Associate & $2009 \pm 7.7$ & 12 & $2016 \pm 3.9$ & 4 & $2010 \pm 7.6$ & 28 & $2016 \pm 1.4$ & 2 \\
\hline Assistant & $2018 \pm 2.1$ & 6 & $2019 \pm 2.1$ & 2 & $2017 \pm 4.2$ & 26 & $2019 \pm 1.9$ & 7 \\
\hline
\end{tabular}

participation of individuals from underrepresented groups. In spring 2021, CNS issued a statement on the missing children of the Kamloops Indian Residential School that acknowledged the historic role of the nutrition sector in failing to protect the health and safety of residential children and emphasizing an obligation to engage in actions toward reconciliation (Canadian Nutrition Society 2021a). CNS also hosted a discussion forum on "Equity, Diversity and Inclusion (EDI): What are your perceptions of EDI in nutrition? What would you like to see CNS do?" at their April 2021 annual conference. This was followed by a survey sent to its members during the summer of 2021 to understand their perspectives on equity, diversity, and inclusion in the organization and the field of nutrition. On Canada's first National Day for
Truth and Reconciliation, CNS hosted a special webinar, "Out of the Darkness and into the Light", to educate nutrition professionals about how Canadian government policies created conditions of malnutrition in Indigenous people who continue to be disproportionately affected by malnutrition and diet-related health problems (Canadian Nutrition Society 2021b). In 2022, CNS initiated a 3-part series of webinars supporting equity within nutrition, the first being "From Bias to Belonging: Moving Beyond Buzzwords to Advance Equity and Justice in the Context of Nutrition".

These actions to increase awareness are important since most nutrition- and obesity-focused professional societies have not systematically assessed their members in terms of diversity or career 
opportunity (Carson et al. 2022). While women professors may not be underrepresented in human nutrition, women speakers are still underrepresented at academic medical conferences (Ruzycki et al. 2019). Moreover, the SARS-CoV-2 pandemic has caused significant disparities in academic productivity by gender and child age (Krukowski et al. 2021) and there is risk of a secondary epidemic of lost early career women scientists (Cardel et al. 2020a). Every effort is needed to sustain and retain junior women professors. Exceptional candidates, whether women, racialized, or Indigenous, are more likely to be excluded, overlooked, and/or evaluated inaccurately during hiring, advancement, and promotion (Henry et al. 2017a). Underrepresented faculty are often responsible for creating a more diverse and inclusive culture (Jimenez et al. 2019). Implicit bias in teaching evaluations, grant funding decisions, and socio-cultural factors impedes careers (Cardel et al. 2020b). Training to recognize and manage implicit bias can be effectively integrated into health professional curricula (Sukhera and Watling 2018) and learning to recognize implicit bias can empower individuals to make meaningful and sustainable changes (Gonzalez et al. 2021).

This study is limited by a subjective assignment to social constructs of white, racialized, Indigenous, women, and men. Social constructs based on beliefs and assumptions, not biology, affect individual opportunities and experiences. Despite the common use of race in nutrition literature, the practice validates the social classification when the application of socio-economic and environmental characteristics might be more appropriate (Duggan et al. 2020). The survey is also limited because it does not include all human nutrition-related scholars and scientists involved in teaching and research at Canadian universities. However, by attempting to characterize 190 assistant, associate, and full professors of human nutrition at 20 Canadian universities, I hope to encourage individuals involved in human nutrition education research in Canada to examine their daily experience for evidence of "obliviousness about unearned advantage" (McIntosh 2019), i.e., privilege, and to participate in the elimination of cultural and institutional barriers that systematically over-empower certain groups and discriminate against others. By rendering systemic, often invisible, privilege systems obsolete, the nutrition community, and Canada, will become stronger through greater diversity, equity, and inclusivity.

\section{Competing interests statement}

The opinions expressed in this paper are those of the author and do not represent any organization. M.I. McBurney serves on the Canadian Nutrition Society Equity, Diversity, and Inclusion Working Group (chair); the Department of Human Health and Nutritional Sciences Equity, Diversity and Inclusion Committee, University of Guelph (member); and the Board of Directors of the American Society for Nutrition (member). He holds or has held consulting agreements in the past 3 years with Council for Responsible Nutrition; Church \& Dwight; DSM Nutritional Products; International Life Sciences Institute, North America; McCormick; OmegaQuant Analytics; PepsiCo; and VitaMe Technologies.

\section{References}

Appel-Cresswell, S., Blanchet, P.J., Wysocki, J., and Postuma, R.B. 2019. Gender and funding success. Lancet, 393(10187): 2195-2196. doi:10.1016/S01406736(19)31107-9. PMID:31162073.

Canada Research Chairs. 2017. Equity, Diversity and Inclusion Action Plan. Available from https://www.chairs-chaires.gc.ca/program-programme/equityequite/action_plan-plan action-eng.aspx. [Accessed 9 January 2022.]

Canada Research Chairs. 2021. Program statistics. Available from https:/ www.chairs-chaires.gc.ca/about_us-a_notre_sujet/statistics-statistiques-eng. aspx\#2. [Accessed 9 January 2022.]

Canadian Centre for Diversity and Inclusion. 2022. Glossary of terms: a reference tool. Canadian Centre for Diversity and Inclusion. Available from https://ccdi.ca/media/3150/ccdi-glossary-of-terms-eng.pdf.

Canadian Nutrition Society. 2021a. CNS statement on the missing children on the Kamloops Indian Residential School. [Press release.] Available from https://cns-scn.ca/organization/cns-statement-kamloops-indian-residentialschool.
Canadian Nutrition Society. 2021b. Special webinar: out of the darkness and into the light. Available from https://cns-scn.ca/events/2021/09/30/specialwebinar-out-of-the-darkness-and-into-the-light.

Cardel, M.I., Dean, N., and Montoya-Williams, D. 2020a. Preventing a secondary epidemic of lost early career scientists. Effects of COVID-19 pandemic on women with children. Ann. Am. Thorac. Soc. 17(11): 1366-1370. doi:10.1513/AnnalsATS.202006-589IP. PMID:32667850.

Cardel, M.I., Dhurandhar, E., Yarar-Fisher, C., Foster, M., Hidalgo, B., McClure, L.A., et al. 2020b. Turning chutes into ladders for women faculty: a review and roadmap for equity in academia. J. Womens Health, 29(5): 721-733. doi:10.1089/jwh.2019.8027. PMID:32043918.

Carson, T.L., Cardel, M.I., Stanley, T.L., Grinspoon, S., Hill, J.O., Ard, J., et al. 2022. Racial and ethnic representation among a sample of nutrition- and obesity-focused professional organizations in the United States. Obesity, 30(2): 292-296. doi:10.1002/oby.23310. PMID:34658155.

Dengate, J., Farenhorst, A., Peter, T., and Franz-Odendaal, T. 2021. Gender inequality in research and service amongst natural sciences and engineering professors in Canada. Int. J. Gender Sci. Technol. 13(1): 23-42. doi:10.4314/ijest.v13i3.3.

Dryfhout, V.L., and Estes, S.B. 2010. Explaining the gender gap in professors' intentions to leave. Sociol. Focus, 43(2): 109-127. doi:10.1080/00380237.2010. 10571371.

Duggan, C.P., Kurpad, A., Stanford, F.C., Sunguya, B., and Wells, J.C. 2020. Race, ethnicity, and racism in the nutrition literature: an update for 2020. Am. J. Clin. Nutr. 112(6): 1409-1414. doi:10.1093/ajcn/nqaa341. PMID:33274358.

Giannakeas, V., Sopik, V., and Narod, S. 2019. Gender bias in CIHR Foundation grant awarding. Lancet, 393(10187): 2195. doi:10.1016/S0140-6736(19) 31103-1. PMID:31162072.

Gonzalez, C.M., Lypson, M.L., and Sukhera, J. 2021. Twelve tips for teaching implicit bias recognition and management. Med. Teach. 43(12): 13681373. doi:10.1080/0142159X.2021.1879378. PMID:33556288.

Henry, F., James, C., Li, P.S., Kobayashi, A., Smith, M.S., Ramos, H., and Enakshi, D., 2017a. The equity myth: racialization and indigeneity at Canadian universities. UBC Press, Vancouver, BC. Available from http:/ books.scholarsportal.info/viewdoc.html?id=/ebooks/ebooks3/upress/2017-07-24/ 1/9780774834902. [Accessed 25 October 2021.

Henry, F., Kobayashi, A., and Choi, A. 2017b. Representational analysis: comparing Canada, the United States, the United Kingdom, and Australia. In The Equity Myth: Racialization and Indigeneity at Canadian Universities. UBC Press, Vancouver, BC. pp. 24-45.

Jimenez, M.F., Laverty, T.M., Bombaci, S.P., Wilkins, K., Bennett, D.E., and Pejchar, L. 2019. Underrepresented faculty play a disproportionate role in advancing diversity and inclusion. Nat. Ecol. Evol. 3(7): 1030-1033. doi:10.1038/ s41559-019-0911-5. PMID:31160738.

Krukowski, R.A., Jagsi, R., and Cardel, M.I. 2021. Academic productivity differences by gender and child age in science, technology, engineering, mathematics, and medicine faculty during the COVID-19 pandemic. J. Womens Health, 30(3): 341-347. doi:10.1089/jwh.2020.8710. PMID:33216682.

McIntosh, P. 2019. White privilege and male privilege: a personal account of coming to see correspondences through work in women's studies (1988). In On Privilege, Fraudulence, and Teaching as Learning. 1st ed. Routledge. pp. 17-28. doi:10.4324/9781351133791-3.

Reithmeier, R., O'Leary, L., Zhu, X., Dales, C., Abdulkarim, A., Aquil, A., et al. 2019. The 10,000 PhDs project at the University of Toronto: using employment outcome data to inform graduate education. PLoS One, 14(1): e0209898. doi:10.1371/journal.pone.0209898. PMID:30650157.

Ruzycki, S.M., Fletcher, S., Earp, M., Bharwani, A., and Lithgow, K.C. 2019. Trends in the proportion of female speakers at medical conferences in the United States and in Canada, 2007 to 2017. JAMA Netw. Open, 2(4): e192103. doi:10.1001/jamanetworkopen.2019.2103. PMID:30977853.

Statistics Canada. 2016. Census Profile, 2016 Census. Available from https:// www12.statcan.gc.ca/census-recensement/2016/dp-pd/prof/details/page.cfm? Lang $=\mathrm{E} \& \mathrm{Geo} 1=\mathrm{PR} \&$ Code $1=01 \& \mathrm{Geo} 2=\mathrm{PR} \&$ Code $2=01 \&$ SearchText $=$ Canada $\&$ SearchType=Begins\&SearchPR=01\&B1=Visible\%20minority\&TABID=1\&type=1. [Accessed 12 January 2022.]

Statistics Canada. 2017. Visible minority and population group reference guide, Census of population, 2016. Available from http://publications.gc. ca/collections/collection_2017/statcan/98-500-x/98-500-x2016006-eng.pdf. [Accessed 10 January 2022.]

Statistics Canada. 2018. Number and salaries of full-time teaching staff at Canadian universities (final), 2017/2018. Available from https://www150. statcan.gc.ca/n1/daily-quotidien/181115/dq181115b-eng.htm. [Accessed 13 January 2022.]

Sukhera, J., and Watling, C. 2018. A framework for integrating implicit bias recognition into health professions education. Acad. Med. 93(1): 35-40. doi:10.1097/ACM.0000000000001819. PMID:28658015.

Universities Canada. 2019. Equity, diversity and inclusion at Canadian Universities: Report on the 2019 national survey. Available from https://www. univcan.ca/wp-content/uploads/2019/11/Equity-diversity-and-inclusion-at-Canadianuniversities-report-on-the-2019-national-survey-Nov-2019-1.pdf.

Witteman, H.O., Hendricks, M., Straus, S., and Tannenbaum, C. 2019. Are gender gaps due to evaluations of the applicant or the science? A natural experiment at a national funding agency. Lancet, 393(10171): 531-540. doi:10.1016/S0140-6736(18)32611-4. PMID:30739688. 